\title{
Motor Axonal Neuropathy Associated With Idiopathic $\mathrm{CD4}^{+}$T-Lymphocytopenia
}

\author{
Tae Im Yi, MD, Bo Ra Kim, MD, In Soo Han, MD, Bo Kyoung Kim, MD
}

Department of Rehabilitation Medicine, Daejin Medical Center Bundang Jesaeng General Hospital, Seongnam, Korea

Idiopathic $\mathrm{CD}^{+} \mathrm{T}$-lymphocytopenia is a rare immune disorder characterized by an unexplained deficit of $\mathrm{CD} 4^{+} \mathrm{T}$ cells and results in various opportunistic infections. Herein, we report a case of new onset weakness in a 10-yearold boy secondary to motor axonal neuropathy associated with idiopathic CD4 ${ }^{+} \mathrm{T}$-lymphocytopenia. The patient was referred to rehabilitation for an evaluation of progressive weakness involving all four limbs. A subsequent nerve conduction study and needle electromyography identified motor axonal neuropathy. At that time, laboratory studies specific to the differential diagnosis of motor axonal neuropathy were performed; however, the abnormality noted was a decreased $\mathrm{CD} 4{ }^{+} \mathrm{T}$-lymphocyte count. Motor axonal neuropathy represents an uncommon manifestation of idiopathic $\mathrm{CD}^{+} \mathrm{T}$-lymphocytopenia and is probably associated with an underlying immune process.

Keywords Axonal neuropathy, Idiopathic CD4-positive T-lymphocytopenia

\section{INTRODUCTION}

Idiopathic $\mathrm{CD}^{+} \mathrm{T}$-lymphocytopenia is defined by the following criteria established by the United States Centers for Disease Control and Prevention in 1992 [1]: 1) a $\mathrm{CD} 4^{+} \mathrm{T}$ cell count below 300 cells $/ \mu \mathrm{L}$ or a $\mathrm{CD} 4^{+}$percentage below $20 \%$ occurring on at least two separate laboratory studies, and 2) the absence of concomitant human immunodeficiency virus (HIV) infection or other im-

Received December 8, 2011; Accepted March 23, 2012

Corresponding author: Bo Ra Kim

Department of Rehabilitation Medicine, Daejin Medical Center Bundang Jesaeng Hospital, 20 Seohyeon-ro 180beon-gil, Bundang-gu, Seongnam 463-774, Korea

Tel: +82-31-779-0395, Fax: +82-31-779-0635, E-mail: 007bora@hanmail. net

(c) This is an open-access article distributed under the terms of the Creative Commons Attribution Non-Commercial License (http://creativecommons. org/licenses/by-nc/3.0) which permits unrestricted noncommercial use, distribution, and reproduction in any medium, provided the original work is properly cited.

Copyright (C) 2013 by Korean Academy of Rehabilitation Medicine munodeficiency. To date, the underlying etiology of idiopathic $\mathrm{CD}^{+} \mathrm{T}$-lymphocytopenia is not yet understood; moreover, the associated clinical presentation can vary from an asymptomatic state to that of life-threatening severe opportunistic infections [2].

Motor axonal neuropathy is characterized clinically by weakness without sensory loss, with electrophysiological studies revealing decreases in the compound muscle action potential amplitude without evidence of demyelination or sensory involvement, and through pathologic findings indicating macrophage infiltration [3,4]. Many conditions have been associated with motor axonal neuropathy, including Charcot-Marie-Tooth neuropathy type 2 , porphyrism, acute motor axonal neuropathy (AMAN, a subtype of Guillain-Barre syndrome), and several toxininduced neuropathies (hexacarbon inhalation, amiodarone, chloroquine) [4].

This case report describes a rare motor axonal neuropathy associated with idiopathic $\mathrm{CD} 4^{+} \mathrm{T}$-lymphocytopenia 
in the absence of any other cause. While demyelinating polyneuropathies associated with serum immunoglobulin A deficiency [5] and HIV infection [6,7] have been described in the literature, no isolated cases of motor axonal neuropathy have been reported. We identify this atypical case of motor axonal neuropathy associated with idiopathic $\mathrm{CD}^{+}$T-lymphocytopenia through laboratory testing as well as neurologic and electrodiagnostic exams; the results are reported here with a literature review.

\section{CASE REPORT}

A 10-year-old boy with no significant birth or family history was hospitalized in the pediatric ward of our hospital for recurrent respiratory infections. Per the patient's medical record, he exhibited normal development, though he was hospitalized at 16 months of age for pneumonia. Since that time, the patient was repetitively hospitalized for various infections, including pneumonia, otitis media, and paranasal sinusitis. Given these recurrent infections, an underlying immunodeficiency was suspected. A subsequent laboratory workup was performed, revealing normal serum quantitative immunoglobulin and complement levels as well as a marked decrease in $\mathrm{CD}^{+} \mathrm{T}$ cells. The patient was then diagnosed with idiopathic $\mathrm{CD} 4^{+} \mathrm{T}$-lymphocytopenia at the age of 5 , given his history of recurrent infections in the setting of a low $\mathrm{CD}^{+} \mathrm{T}$ cell count. All secondary infections were then conservatively treated with antibiotics, and the patient was closely followed as an outpatient, though immunotherapy was not performed.

Several years later, in 2010, the patient complained of generalized weakness of his four extremities, although he reported that these symptoms did not significantly affect his daily life. However, as this limb weakness continued to worsen, the patient was then referred to our clinic in the Department of Rehabilitation Medicine in January 2011 for further evaluation and treatment. At the time of his first examination, the patient was $124 \mathrm{~cm}$ tall, weighed $19.4 \mathrm{~kg}$, and had a body mass index of 12.36 , which is defined as being underweight. Prominent muscular atrophy of the limbs was noted on the exam (Fig. 1). Using the Medical Research Council (MRC) scale, manual muscle testing was then performed revealing the following: upper extremity shoulder flexion $2 / 5$, abduction $2 / 5$, elbow flexion $3 / 5$, extension $2 / 5$, wrist flexion $3 / 5$, and extension $2 / 5$; lower extremity hip flexion $2 / 5$, extension

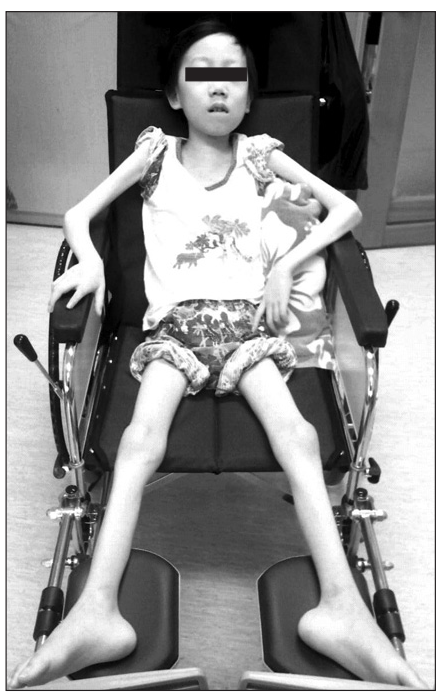

Fig. 1. Picture of patient showing severe generalized muscle atrophy.

$1 / 5$, knee flexion $1 / 5$, extension $2 / 5$, ankle dorsiflexion $1 / 5$, great toe extension $3 / 5$, and plantarflexion $2 / 5$. All results were symmetric for the contralateral upper and lower extremities. Additionally, no sensory abnormalities were detected in temperature, tactile, position, or vibration sensation. The patient's deep tendon reflexes for the bilateral biceps and knees were also normal. During the entire exam, the patient was conscious and alert, and the cranial nerve examination was without abnormal findings. The patient was able to turn over in bed, but was unable to sit up from a supine position without assistance. In terms of the degree of independence in daily living, the patient had a Modified Barthel Index (MBI) of 28 , indicating the need for maximal assistance from other people.

A subsequent motor nerve conduction study showed decreased compound muscle action potential amplitude for the left median, ulnar, right peroneal, and tibial nerves, although the latency and nerve conduction velocity were within normal limits. Additional sensory nerve conduction studies were also within normal limits (Table 1). Needle electromyography further revealed increased insertional activity for all examined muscles, with a large amount of abnormal spontaneous activity noted in the paralumbar muscles, left vastus medialis, tibialis anterior, gastrocnemius, right biceps brachii, and abductor pollicis brevis. Specifically, polyphasic motor unit action potentials and reduced motor unit recruitment were observed during muscle contraction (Table 2). A somatosensory evoked potential study of the tibial 
Table 1. Findings of the motor and sensory nerve conduction study

\begin{tabular}{|llccc}
\hline \multicolumn{1}{c}{ Nerve } & Latency $(\mathbf{m s})$ & Amplitude & Velocity (m/sec) \\
\hline \multirow{2}{*}{ Motor } & Right median & 3.2 & $1.3 \mathrm{mV}$ & 52 \\
& Right ulnar & 2.7 & $1.7 \mathrm{mV}$ & 55 \\
& Left peroneal & 4.5 & $1.1 \mathrm{mV}$ & 44 \\
& Left deep peroneal & 4.1 & $2.0 \mathrm{mV}$ & 45 \\
\multirow{2}{*}{ Sensory } & Right median & 1.9 & $66 \mu \mathrm{V}$ & - \\
& Right ulnar & 1.7 & $60 \mu \mathrm{V}$ & - \\
& Left superficial peroneal & 1.8 & $20 \mu \mathrm{V}$ & - \\
\hline
\end{tabular}

Table 2. Findings of needle electromyography

\begin{tabular}{|c|c|c|c|c|c|c|c|c|}
\hline \multirow[t]{2}{*}{ Muscle } & \multirow[t]{2}{*}{ IA } & \multicolumn{3}{|c|}{$\begin{array}{l}\text { Spontaneous } \\
\text { potential }\end{array}$} & \multicolumn{3}{|c|}{$\begin{array}{c}\text { Motor unit action } \\
\text { potential }\end{array}$} & \multirow{2}{*}{$\begin{array}{c}\text { Recruitment } \\
\text { pattern }\end{array}$} \\
\hline & & PSW & Fib & Fasc & Phase & Amplitude & Duration & \\
\hline Left paralumbar (L3-S1) & Increased & +++ & +++ & - & & Normal & Normal & \\
\hline Left vastus medialis & Increased & + & + & - & Polyphasic & Normal & Normal & Single \\
\hline Left gastrocnemius & Increased & ++ & ++ & - & Polyphasic & Normal & Normal & Single \\
\hline Left tibialis anterior & Increased & +++ & +++ & - & Polyphasic & Normal & Normal & $\mathrm{P}-\mathrm{C}$ \\
\hline Right biceps brachii & Increased & ++ & ++ & - & Polyphasic & Normal & Normal & $\mathrm{P}-\mathrm{C}$ \\
\hline Right abductor pollicis brevis & Increased & ++ & ++ & - & Polyphasic & Normal & Normal & $\mathrm{P}-\mathrm{C}$ \\
\hline Right gastrocnemius & Increased & +++ & +++ & - & Polyphasic & Normal & Normal & $\mathrm{P}-\mathrm{C}$ \\
\hline Right vastus medialis & Increased & +++ & +++ & - & Polyphasic & Normal & Normal & Single \\
\hline
\end{tabular}

IA, insertional activity; PSW, positive sharp wave; Fib, fibrillation potential; Fasc, fasciculation; P-C, partial to complete.

nerve; however, it did not reveal any specific findings.

Results from an additional electrodiagnostic study indicated that the motor nerves of the upper and lower extremities were primarily affected, with a marked reduction in compound muscle action potential amplitude in the setting of a normal conduction velocity pattern. The results suggested a major axonal involvement rather than a demyelinating process. A diagnosis of the motor axonal type was then reached, given the results from the sensory nerve studies and lack of associated clinical symptoms. A number of additional diagnostic studies were then performed in order to identify the underlying etiology of the process, with no significant finding noted on the magnetic resonance imaging of the brain, vertebrae, and cerebrospinal fluid (CSF). Serum muscle enzymes, electrolytes, thyroid function tests, and liver function tests were also within the normal range. Additionally, serum immunoglobulin GM1 and GD1 were both negative as was the antibody testing for all associated infectious dis- eases (e.g., HIV) and abdominal ultrasonography (Table 3 ). The patient was found to have a decreased number of $\mathrm{CD} 4^{+} \mathrm{T}$ cells on lymphocyte subtyping (Table 3 ). A sural nerve biopsy was not performed as the sensory nerve function was found to be normal in the electrodiagnostic study.

Clinically, the patient had significant difficulty in carrying out daily living activities, including walking, due to marked muscle weakness. Rehabilitation treatment focused primarily on wheelchair transfer training, joint contracture prevention, and posture maintenance, since active rehabilitation was not possible due to the patient's recurrent infections. As the pulmonary function testing showed decreased respiratory function, pulmonary rehabilitation was also initiated.

\section{DISCUSSION}

Decreases in $\mathrm{CD} 4^{+} \mathrm{T}$-lymphocytes can occur in a num- 
Table 3. Laboratory test results

\begin{tabular}{|c|c|c|}
\hline Laboratory test & Value & Reference \\
\hline Creatine kinase (IU/L) & 50 & $58-348$ \\
\hline Lactate dehydrogenase (IU/L) & 423 & $263-450$ \\
\hline AST/ALT (IU/L) & $24 / 120$ & $0-40$ \\
\hline Vitamin B1 $(\mu \mathrm{g} / \mathrm{L})$ & 60.20 & 60.20 \\
\hline Vitamin B12 (pg/mL) & 530 & $197-894$ \\
\hline Folate $(\mathrm{ng} / \mathrm{mL})$ & 14.07 & $2.2-17.5$ \\
\hline Ferritin (ng/mL) & 439.80 & $30-400$ \\
\hline T-protein/albumin (g/dL) & $8.5 / 4.3$ & $6-8 / 3.3-5.2$ \\
\hline Globulin (g/dL) & 3.2 & $1.1-3.5$ \\
\hline Free T4 (ng/dL) & 1.20 & $0.93-1.70$ \\
\hline $\mathrm{TSH}(\mathrm{IU} / \mathrm{mL})$ & 3.58 & $0.27-4.2$ \\
\hline Anti-GM1 IgG/IgM & Negative & Negative \\
\hline Anti-nuclear Ab & Negative & Negative \\
\hline $\mathrm{HIV} \mathrm{Ag/Ab}$ & Negative & Negative \\
\hline \multicolumn{3}{|l|}{ Serum immunoglobulin (Ig) } \\
\hline $\operatorname{IgG}(\mathrm{mg} / \mathrm{dL})$ & 911 & $800-1,700$ \\
\hline IgA (mg/dL) & 155 & $100-490$ \\
\hline $\operatorname{IgE}(\mathrm{IU} / \mathrm{mL})$ & $<0.1$ & $0.1-200$ \\
\hline $\operatorname{IgM}(\mathrm{mg} / \mathrm{dL})$ & 245 & $20-320$ \\
\hline C3 (mg/dL) & 117 & \\
\hline $\mathrm{C} 4(\mathrm{mg} / \mathrm{dL})$ & 20 & \\
\hline CH50 (U/mL) & 41.5 & \\
\hline \multicolumn{3}{|l|}{ CSF study } \\
\hline White blood cell $(/ \mu \mathrm{L})$ & 5 & $0-5$ \\
\hline Glucose (mg/dL) & 60 & $45-60$ \\
\hline Protein $(\mathrm{mg} / \mathrm{dL})$ & 58 & $12-60$ \\
\hline Gram stain and culture & No growth & \\
\hline \multicolumn{3}{|l|}{ Lymphocyte subset (\%) } \\
\hline CD3 (T cell) & 67.60 & $54-82$ \\
\hline CD4 (T helper) & 16.20 & $24-55$ \\
\hline CD8 (T suppressor) & 20.80 & $11-38$ \\
\hline CD19 (B cell) & 9.1 & $5-23$ \\
\hline Natural killer cell & 31.6 & $5-35$ \\
\hline
\end{tabular}

AST, aspartate aminotransferase; ALT, alanine aminotransferase; TSH, thyroid-stimulating hormone; CSF, cerebrospinal fluid; HIV, human immunodeficiency virus; $\mathrm{Ag} / \mathrm{Ab}$, antigen/antibody.

ber of settings-including viral and mycobacterial infections, Brucellosis, malnutrition, autoimmune diseases, and acquired immune deficiency syndrome (AIDS)despite the fact that the associated symptoms are usually temporary and not severe [8]. Conversely, while the exact prevalence of idiopathic $\mathrm{CD}^{+} \mathrm{T}$-lymphocytopenia is not known, it is estimated to be extremely low, as no cases were identified in a screening study of 2,028 blood donors from 1994 [2]. The clinical manifestations of idiopathic $\mathrm{CD} 4^{+} \mathrm{T}$-lymphocytopenia vary from an asymptomatic state to the recurrent severe opportunistic infections similar to those that occur in the setting of AIDS. Although rare cases associated with Sjogren's syndrome, pulmonary sarcoidosis, Down syndrome, and non-Hodgkin's lymphoma exist in the literature, no such reports exist regarding motor axonal neuropathy verified by electrodiagnostic assay.

Idiopathic $\mathrm{CD} 4^{+} \mathrm{T}$-lymphocytopenia can likely be induced by a variety of underlying mechanisms, with proposed hypotheses including decreases in $\mathrm{T}$ cell progenitors, increases in $\mathrm{T}$ cell apoptosis, and antibody production against $\mathrm{CD} 4^{+} \mathrm{T}$ cells. Neuropathy may also result from similar immunological mechanisms [9]. As noted in idiopathic $\mathrm{CD} 4^{+}$T-lymphocytopenia, decreases in $\mathrm{CD}^{+}{ }^{+} \mathrm{T}$-lymphocytes are also seen in the setting of HIV infection. HIV-associated neuropathy is now believed to be immune-mediated, with cytokine release from macrophages acting as the primary neuronal insult. Other nonimmunological mechanisms include vitamin $B_{12}$ deficiency and an idiopathic neurotoxic effect from a number of HIV medications $[6,7]$. Accordingly, the patient described here could have also developed a neuropathy induced by similar immunological mechanisms.

To rule out nonimmunological causes-such as nutritional deficiencies, infectious etiologies, autoimmune disease, and medications-the patient's nutritional status, HIV status, autoimmune antibody status, and history of medication use were thoroughly evaluated. Further, although the patient was underweight (body mass index=12.36), serum protein, albumin, vitamin $B_{1}$, $\mathrm{B}_{12}$, folic acid, and ferritin levels were all normal, thus, malnutrition-induced neuropathy could be ruled out. When diagnosing idiopathic $\mathrm{CD} 4^{+} \mathrm{T}$-lymphocytopenia, HIV infection must also be ruled out; hence, HIV antigen antibody enzyme-linked immunosorbent assay (ELISA) testing was performed four separate times. As all were negative, HIV infection and associated neuropathy were excluded. Moreover, the patient also received multidrug therapy, including many various antibiotics, for recurrent respiratory infections. However, since he had only been treated in the pediatric ward of our hospital, all of the medications administered since birth were documented in his medical record. Specifically, in the past, the patient 
had been treated with penicillin-class antibiotics, cephalosporins (including first, second, and third generation agents), and carbapenem. At no time were aminoglycosides or sulphonamides, both well-known causes of neuropathy, ever used. Furthermore, as the patient had been intermittently treated with prednisolone, the possibility of an underlying myopathy was also considered. However, as all serum muscle enzyme levels were within normal limits, the motor unit action potential amplitude was within the normal range on needle electromyography, and an early motor unit recruitment pattern was not observed; myopathy was effectively ruled out. Additionally, since the patient did not have a history of intensive care treatment, mechanical ventilation, sepsis, septic shock, or multiple organ dysfunction, critical illness neuropathy-a condition mostly involving both motor and sensory nerves-was also excluded. Other motor neuron diseases (e.g., spinal muscular atrophy) were also excluded for the following reasons: a fasciculation potential was not observed on either of the two performed electromyography, the motor unit action potential duration and amplitude were both within normal limits, the patient's clinical symptoms developed at age 10 , bulbar palsy was absent, and the patient's family history was found on the genetic testing.

AMAN, a subtype of Guillain-Barre syndrome, might present as motor axonal neuropathy on the electrodiagnostic study. However, our patient's clinical symptoms were significantly different from AMAN, whereby progress is dramatic and recovery of the muscular strength is rapid. Exclusion of AMAN was then confirmed given the normal CSF testing, negative serum anti-GMl antibody assay, and lack of therapeutic response to glucocorticoids. Charcot-Marie-Tooth disease type 2 can also manifest as motor axonal neuropathy in a similar fashion to AMAN on the electrodiagnostic study. However, CharcotMarie-Tooth disease was ruled out by the physical exam (specifically the presence of cavus foot and weakness of the lower limbs) and family history. As described above, a variety of tests were performed in order to identify the underlying cause of the patient's motor axonal neuropathy, all of which were within normal limits, with the exception of the findings specific for idiopathic $\mathrm{CD} 4^{+} \mathrm{T}$ lymphocytopenia.

Currently, the therapy for idiopathic $\mathrm{CD} 4^{+} \mathrm{T}$-lymphocytopenia focuses on the treatment and prevention of opportunistic infections, although interleukin-2 has been reported as being effective in increasing the $\mathrm{CD} 4^{+}$ T-lymphocyte count [9]. Biopsy was not performed in this case, as the patient's parents were unwilling to give consent, which may represent one limitation of this case report. However, a diagnosis of motor axonal neuropathy was nonetheless reached by clinical, physical, and electrodiagnostic examinations.

In conclusion, motor axonal neuropathy secondary to idiopathic $\mathrm{CD}^{+} \mathrm{T}$-lymphocytopenia is very rare, particularly in a pediatric population. Currently, the exact etiologic mechanisms for these processes are not known, and as such, no causality can be determined. Further studies are necessary to better describe the etiology and immunological characteristics of idiopathic $\mathrm{CD} 4^{+} \mathrm{T}-\mathrm{lym}$ phocytopenia, as well as to establish the diagnostic criteria, the treatment protocol, and further assess the overall prognosis.

\section{CONFLICT OF INTEREST}

No potential conflict of interest relevant to this article was reported.

\section{REFERENCES}

1. Centers for Disease Control (CDC). Unexplained CD4 $4^{+}$ T-lymphocyte depletion in persons without evident HIV infection: United States. MMWR Morb Mortal Wkly Rep 1992;41:541-5.

2. Busch MP, Valinsky JE, Paglieroni T, Prince HE, Crutcher GJ, Gjerset GF, et al. Screening of blood donors for idiopathic $\mathrm{CD} 4^{+} \mathrm{T}$-lymphocytopenia. Transfusion 1994;34:192-7.

3. Park KT, Ku BD. Two cases of acute motor axonal neuropathy showing rapid clinical recovery. J Korean Assoc EMG Electrodiagn Med 2008;10:157-61.

4. Dumitru D, Amato AA, Zwarts MJ. Electrodiagnostic medicine. 2nd ed. Philadelphia: Hanley \& Belfus; 2002.

5. Vital A, Fontan D, Petry KG, Lagueny A, Pillet P, Vital C. Serum immunoglobulin A deficiency in relapsing inflammatory demyelinating polyneuropathy. Muscle Nerve 1999;22:543-5.

6. Ferrari S, Vento S, Monaco S, Cavallaro T, Cainelli F, Rizzuto N, et al. Human immunodeficiency virus- 
Tae Im Yi, et al.

associated peripheral neuropathies. Mayo Clin Proc 2006;81:213-9.

7. Brew BJ. The peripheral nerve complications of human immunodeficiency virus (HIV) infection. Muscle Nerve 2003;28:542-52.
8. Misbah SA, Chapel HM. Idiopathic CD4 $4^{+}$T-lymphocytopenia. Lancet 1992;340:609.

9. Luo L, Li T. Idiopathic CD4 lymphocytopenia and opportunistic infection: an update. FEMS Immunol Med Microbiol 2008;54:283-9. 